locally compact, has a less complete theory and is outside the scope of the present work.) In the generalized theory, the role of the circular functions is played by the matrix elements of the irreducible matrix representations of the group. It is remarkable how many of the theorems about Fourier series survive such a broad generalization.

The development of the theory requires a great deal of special knowledge about topological groups, integration theory and invariant measures on groups. Even though the authors do not hesitate to refer to standard texts whenever possible, their troatment of this preparatory material occupies the first half of the volume, and constitutes a valuable addition to the text-books of these subjects. Only in the last two chapters, on convolutions and group representations and on characters and duality of locally compact Abelian groups, does the harmonic analysis proper begin. Full details of the subject are reserved for the second volume. There are appendixes on Abelian groups, topological linear spaces and normed algebras, and a good bibliography.

Text-books at this advanced level not uncommonly make very heavy reading, and so it is a pleasure to report that the authors have obviously made great efforts to ease the way for those readers who are not already experts. Thus the proofs are written out in very good detail. An abbreviated first route through the book is recommended. Nearly all the twenty-six sections contain a large collection of examples and miscellaneous theorems to round out the general theory. There are also notes commenting on the history of the leading ideas of the section, and giving references to alternative troatments and further developments. Thanks are due to the authors for producing $\mathbf{a}$ book which will serve well both students and experts in its subject.

T. A. S. JACKSON

\section{Textbook of Organic Chemistry}

By Prof. Alexander Gero. Pp. ix +679. (New York and London: John Wiley and Sons, Inc., 1963.) $72 s$.

DROF. GERO has had long experience of industrial research and university teaching, and the latter is the basis of this book. Although it starts with an introductory survey of organic chemistry and of electronic theory it is a university book rather than one for schools.

A preliminary fifty-page chapter deals with relatively simple compounds and their reactions. A second one deals with fundamental theories, explaining the nature of organic reactions on the valence-bond theory rather than on molecular-orbital theory which Prof. Gero finds less suitable for many of his students owing to their inadequate background of physies and mathematics. The latter theory is included in a penultimate chapter. A final chapter is on physical methods used in organic chemistry. It discusses concisely the use of the polarimeter and $p \mathrm{H}$ meters, of ultra-violet and infra-red spectroscopy, molecular resonance and various resonance spectra.

Separation of aliphatic from aromatic compounds is abandoned after the preliminary chapter, and related typos, for example, alcohols and phenols, are considered togethor. Physical proporties receive full consideration, but the aim is not a load of facts but a balance of them with theory so that the student shall "understand how and why reactions take place". Practical instructions are not part of the book. The main part of the book comprises twenty-three chapters on groups of compounds selected for their importance in giving a worth-while picture of the subject, two on stereochemistry and one each on the hydrocarbon-based industries and the plastics industry and polymerization. There are two chapters on polyfunctional compounds, three on hoterocycles and one each on isoprenoids and steroids. Many chapters conclude with a useful summary and almost all of them with a selection of questions.

The book is produced to the high standards that are to be expected from American text-books. H. DUNNICLIFF

\section{Birds of Hampshire and the Isle of Wight}

By Edwin Cohen. Pp. xii $+278+16$ plates. (Edinburgh and London: Oliver and Boyd, Ltd., 1963.) $30 s$. net.

NE of the signs that birds are the most popular group of animals among British naturalists is the existence, for every county in England and most of those in Wales, of a book or at least a booklet devoted entirely to their birds. But so great has been the increase in our knowledge of the migration and breeding distribution of British birds resulting from the remarkable upsurge of amateur observation in the past thirty years, that any county avi-fauna not published within that period (or indeed within the past ten years) is likely to be seriously out of date. This was certainly the case with Hampshire and the Isle of Wight, where the standard work dated from 1905, and this new book by Edwin Cohen, who has for so long been associated with the county's ornithology, will therefore be most welcome to bird watchers both in and out of Hampshire.

Much of the value of such a work depends on the thoroughness with which the author has both combed the vast and scattered literature and vetted the records of rarities; in these respects Mr. Cohen has been exemplary. Though the main part of the book consists in the usual annotated systematic list of the individual bird species, thore are also some useful introductory chapters. D. W. Wray writes on geology, Mrs. A. K. Hunt on botany, and six authors deal with birds in relation to habitat and land use in the county divided into seven regions: J. S. Ash on the Fordingbridge area, D. F. Billett on the south-east corner, E. L. Jones on northwest Hampshire, J. Stafford on the Isle of Wight, J. H. Taverner on the Winchester area and part of the Solent shore, and the author himself on his home region, the New Forest.

R. S. R. FITTER

\section{A Study of Reptiles and Amphibians including their Care as Pets}

By Alfred Leutscher. Pp. 80. (London: Blandford Press, Ltd., 1963.) 10s. $6 \dot{d}$.

A LFRED LEUTSCHER has written yet another A popular account of reptiles and amphibians intended for the lay reader. Three-quarters of the text is a thumbnail sketch of the origin, evolution, classification, biology and habits of the reptiles and amphibians, with a short chapter on popular misconceptions. Ths remaining quarter concerns the care of these creatures in captivity and simple experimonts and observations that nature groups and others might carry out. For the person to whom herpetology is a new interest a fair background to the subject is given, but some wildly inaccurate facts and figures are also presented and an outdated classification of the amphibia used, which suggest that the author is unfamiliar with the literature and with many of the animals.

A fow examples will suffice. In describing caecilians, the author states that "behind each eye is a small tentacle on the face". The leathery turtle is defined as having "a soft leathery skin with only a few bones in it"; there are in fact many hundreds. The pineal eye of the tuatara is reported as possessing an iris. (My italics.) But the most astonishing definition is that given to the Reptilia: "they are distinguished from all other vertebrate animals in having lungs and limbs, and their bodies covered in a protection of scales". Into this category the uninitiated might gleofully place the armadillo, pangolin and the lung fishes. While the photographs are good, the line drawings are of limited use and some are even grossly inaccurate. If a competent illustrator was not available, reproduction of early figures of snake skulls would have been infinitely more reliable than the author's diagrams, which feature a puzzling arrangement of bones with an apparently fractured pterygoid hinged to the lower jaw.

A. G. C. Grandison 